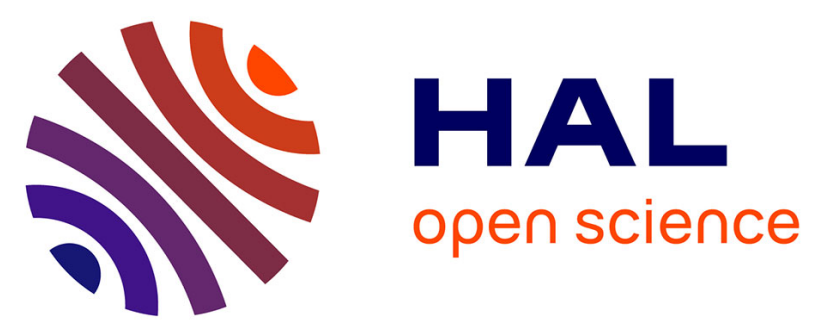

\title{
Trigeminal neuralgia related to megadolichobasilar artery compression: a prospective series of twenty-nine patients treated with gamma knife surgery, with more than one year of follow-up.
}

Constantin Tuleasca, Romain Carron, Noémie Resseguier, Anne Donnet, P Roussel, Jean Gaudart, Marc Levivier, Jean Regis

\section{To cite this version:}

Constantin Tuleasca, Romain Carron, Noémie Resseguier, Anne Donnet, P Roussel, et al.. Trigeminal neuralgia related to megadolichobasilar artery compression: a prospective series of twenty-nine patients treated with gamma knife surgery, with more than one year of follow-up.. Stereotactic and Functional Neurosurgery, 2014, 10.1159/000362172 . hal-01307484

\section{HAL Id: hal-01307484 \\ https://hal-amu.archives-ouvertes.fr/hal-01307484}

Submitted on 26 Apr 2016

HAL is a multi-disciplinary open access archive for the deposit and dissemination of scientific research documents, whether they are published or not. The documents may come from teaching and research institutions in France or abroad, or from public or private research centers.
L'archive ouverte pluridisciplinaire HAL, est destinée au dépôt et à la diffusion de documents scientifiques de niveau recherche, publiés ou non, émanant des établissements d'enseignement et de recherche français ou étrangers, des laboratoires publics ou privés.

\section{(1) $(1) \Theta$}

Distributed under a Creative Commons Attribution - NonCommercial - NoDerivatives 44.0 


\section{Trigeminal Neuralgia Related to Megadolichobasilar Artery Compression: A Prospective Series of Twenty-Nine Patients Treated with Gamma Knife Surgery, with More Than One Year of Fol...}

Article in Stereotactic and Functional Neurosurgery · June 2014

Impact Factor: 2.02 · DOI: 10.1159/000362172 · Source: PubMed

CITATIONS

7

8 authors, including:

\section{Romain Carron}

Assistance Publique Hôpitaux de Marseille 69 PUBLICATIONS 347 CITATIONS

SEE PROFILE

Jean Gaudart

Aix-Marseille Université

185 PUBLICATIONS 1,568 CITATIONS

SEE PROFILE
READS

57
Noemie Resseguier

Aix-Marseille Université

59 PUBLICATIONS 120 CITATIONS

SEE PROFILE

Jean Régis

Assistance Publique Hôpitaux de Marseille

389 PUBLICATIONS 10,021 CITATIONS

SEE PROFILE 


\title{
Trigeminal Neuralgia Related to
} Megadolichobasilar Artery Compression: A Prospective Series of Twenty-Nine Patients Treated with Gamma Knife Surgery, with More
Than One Year of Follow-Up

\author{
Constantin Tuleasca ${ }^{\mathrm{a}, \mathrm{d}-\mathrm{g}}$ Romain Carron ${ }^{\mathrm{a}}$ Noémie Resseguier ${ }^{\mathrm{b}}$ \\ Anne Donnet ${ }^{c}$ Philippe Roussel $^{c}$ Jean Gaudart ${ }^{b}$ Marc Levivier ${ }^{f, g}$ \\ Jean Régis ${ }^{a}$ \\ ${ }^{a}$ Functional and Stereotactic Neurosurgery Unit, INSERM U751, b Department of Public Health and Medical \\ Information, UMR 912 (INSERM-IRD-Université de la Méditerranée), and 'Department of Neurology, Clinical \\ Neuroscience Federation, Centre Hospitalier Universitaire La Timone Assistance Publique-Hôpitaux de Marseille, \\ Marseille, France; dSignal Processing Laboratory (LTS5), Swiss Federal Institute of Technology (EPFL), e Medical \\ Image Analysis Laboratory and ${ }^{\mathrm{f}}$ Neurosurgery Service and Gamma Knife Center, Centre Hospitalier Universitaire \\ Vaudois, and ${ }^{9}$ Faculty of Biology and Medicine, University of Lausanne, Lausanne, Switzerland
}

\section{Key Words}

Megadolichobasilar artery · Trigeminal neuralgia · Gamma Knife surgery

\footnotetext{
Abstract

Background: Trigeminal neuralgia (TN) secondary to megadolichobasilar artery (MBA) compression is considerably difficult to manage surgically. Objective: This study aims to evaluate the safety/efficacy of Gamma Knife surgery (GKS) in this special group of patients. Methods: Between July 1992 and November 2010, 29 patients with $>1$ year of follow-up presenting with MBA compression were treated with GKS at Timone University Hospital. Radiosurgery was performed using a Gamma Knife (model B, C or Perfexion). A single 4-mm isocenter was positioned in the cisternal portion of the trigeminal nerve at a median distance of $9.1 \mathrm{~mm}$ (range: 6-18.2 $\mathrm{mm}$ ) from the emergence. Results: The median follow-up period was 46.1 months (range: 12.9-157.9 months). Initially,
}

all patients (100\%) were pain free; the average time to complete pain relief was 13.5 days (range: $0-240$ days). Their actuarial probability of remaining pain free without medication at $0.5,1$ and 2 years was $93.1,79.3$ and $75.7 \%$, respectively, and remained stable until 13 years after treatment. The actuarial probability of hypoesthesia onset at 6 months was $4.3 \%$; at 1 year it reached $13 \%$ and remained stable until 13 years after treatment. Conclusions: GKS proved to be reasonably safe and effective on a long-term basis as a first-and/ or second-line surgical treatment for TN due to MBA compression.

(c) 2014 S. Karger AG, Basel

\section{Introduction}

Trigeminal neuralgia (TN) - also known as 'tic douloureux', as it was named by the French surgeon Nicholas André [1] - is a serious health problem, with a prevalence

\section{KARGER}

E-Mail karger@karger.com www.karger.com/sfn (c) 2014 S. Karger AG, Basel

$1011-6125 / 14 / 0923-0170 \$ 39.50 / 0$
Jean Régis

Stereotactic and Functional Neurosurgery Department, Hôpital de la Timone 264, Rue Saint Pierre

FR-13385 Marseille (France)

E-Mail jregis@ap-hm.fr 
rate of 4-5 per 100,000 people [2]. Several causes were identified as origins of $\mathrm{TN}$, and vascular compression is considered to be one of the major pathogenic factors [35]. Usually, the vessels involved in the neurovascular conflict are arteries such as the superior cerebellar or anterior inferior cerebellar artery. Less frequently, prominent veins such as the petrosal veins or draining veins of the brainstem are also involved [6].

Microvascular decompression (MVD) of the trigeminal nerve is the most effective operation for treating patients with TN, with long-term cure rates between 69 and $96 \%$ of the cases [7-13]. Sindou et al. [13,14] proposed a surgical classification of the neurovascular compression and its severity, and demonstrated that this is a predictive factor for the results [14]. This classification included the following grading: 1 - simple contact; 2 - distortion, and 3 - marked indentation [14]. In the case of compression of the trigeminal nerve by an ecstatic basilar artery, it is rather difficult to grade the conflict. Megadolichobasilar artery (MBA) compression is usually creating a marked indentation on the nerve and/or the adjacent brainstem, making it difficult to visualize in some patients.

MBA compression has rarely been described in the literature; Jannetta [15] did not refer to this condition in a series of 60 cases with TN due to vascular compression. Many case reports [12, 16-29], and recently a series [30], have described the topic of MBA-related TN, but only a few of them have included the results of decompressive vascular surgery $[12,31]$. There are several problems with MVD in MBA-related TN which render this type of intervention particularly difficult, such as a considerable risk of mobilization of the trigeminal nerve because of the high internal turgor of these large vessels as well as a tendency for the patients to be older and to develop cranial nerve deficits more often than the MVD series as a whole [12]. Beside MVD, other types of treatment have been reported in the literature, such as foramen magnum decompression [17].

Gamma Knife surgery (GKS) is a minimally invasive surgical approach in the armamentarium for refractory TN $[32,33]$. Lars Leksell first introduced the concept of stereotactic radiosurgery in 1951, when he treated a patient suffering from essential TN using a prototypeguiding device linked to a dental X-ray machine $[15,34-$ 36]. Nowadays, the role of GKS in TN has been confirmed by several studies in terms of its safety and efficacy [17, 37-42], although until one year ago, none of them had specifically evaluated TN related to MBA compression. Recently, Park et al. [30] reported on a first series of 20 patients and the results of GKS for TN due to vertebrobasilar ectasia.

Radiosurgery for TN Related to MBA

Compression
Our prospective study evaluates the safety and efficacy of GKS, using three parameters widely accepted in the literature: initial pain cessation, hypoesthesia and the probability of maintaining pain relief.

\section{Subjects and Methods}

\section{Patient Population and Selection}

Between July 1992 and November 2010, 737 patients presenting with intractable TN were treated with GKS and followed up prospectively at Timone University Hospital in Marseille, France. Only patients fulfilling the criteria of the International Headache Society (2003) [43] were accepted for treatment.

An evaluation of the type of trigeminal pain was made according to the classification proposed by Eller et al. [44] into idiopathic TN1 and TN2. While TN1 is typically described as sharp, shooting and electric-shock-like pain with pain-free intervals between the attacks, TN2 is described as aching, throbbing or burning pain for $>50 \%$ of the time which is constant in nature (a constant background pain being the most significant attribute).

From our global series, thirty-three patients presented with TN related to MBA compression, of which 29 had > 1 year of follow-up; their cases were further analyzed in this study.

\section{Radiosurgical Technique}

During the 18 years of the study, various models of the Gamma Knife were used (models B, C, 4C and Perfexion; Elekta Instrument AB, Sweden). After application of the Leksell Model G stereotactic frame (Elekta Instrument $\mathrm{AB}$ ) under local anesthesia, all patients underwent stereotactic magnetic resonance imaging (MRI) and computed tomography (CT) scanning to identify the trigeminal nerve. The MRI sequences used were T2 type CISS without contrast (Siemens) and contrast-enhanced T1-weighted imaging. CT scanning routinely supplements the neuroradiological investigation in order to correct any distortion errors on the MR images.

In the Gamma Unit in Marseille, France, we use the anterior target, which means placing a unique $4-\mathrm{mm}$ isocenter on the cisternal portion of the trigeminal nerve using a very anterior target, located immediately posterior to the gasserian ganglion, as previously described $[33,41]$, at a median distance of approximately 7.5 $\mathrm{mm}$ from the entry point of the trigeminal nerve into the brainstem, if the anatomical conditions allow. We initially give a dose of $90 \mathrm{~Gy}$ at the $100 \%$ isodose point. Beam channel blocking is used depending on the dose received by $10 \mathrm{~mm}^{3}$ of the brainstem; should this dose be $>15$ Gy, we diminish the dose and then start plugging so as to be able to avoid increasing the length of the treated nerve, which could amount for more toxicity (the so-called Flickinger effect) [34].

In the current series, a single 4-mm isocenter was used for all patients and was positioned in the anterior cisternal portion of the trigeminal nerve at a median distance of $9.1 \mathrm{~mm}$ (range: 6-18.2 mm) anteriorly to the emergence of the nerve. Radiosurgical targeting can be very challenging in this special indication. Difficulties were sometimes encountered in visualizing the trigeminal nerve as the compression by the ecstatic MBA, depending on the grade of indentation in the nerve, made the targeting challenging. Figure 1 presents the retrogasserian target, also

Stereotact Funct Neurosurg 2014;92:170-177 
Fig. 1. Retrogasserian target ('Marseille target') in the special anatomical condition of ipsilateral trigeminal nerve compression by the MBA.
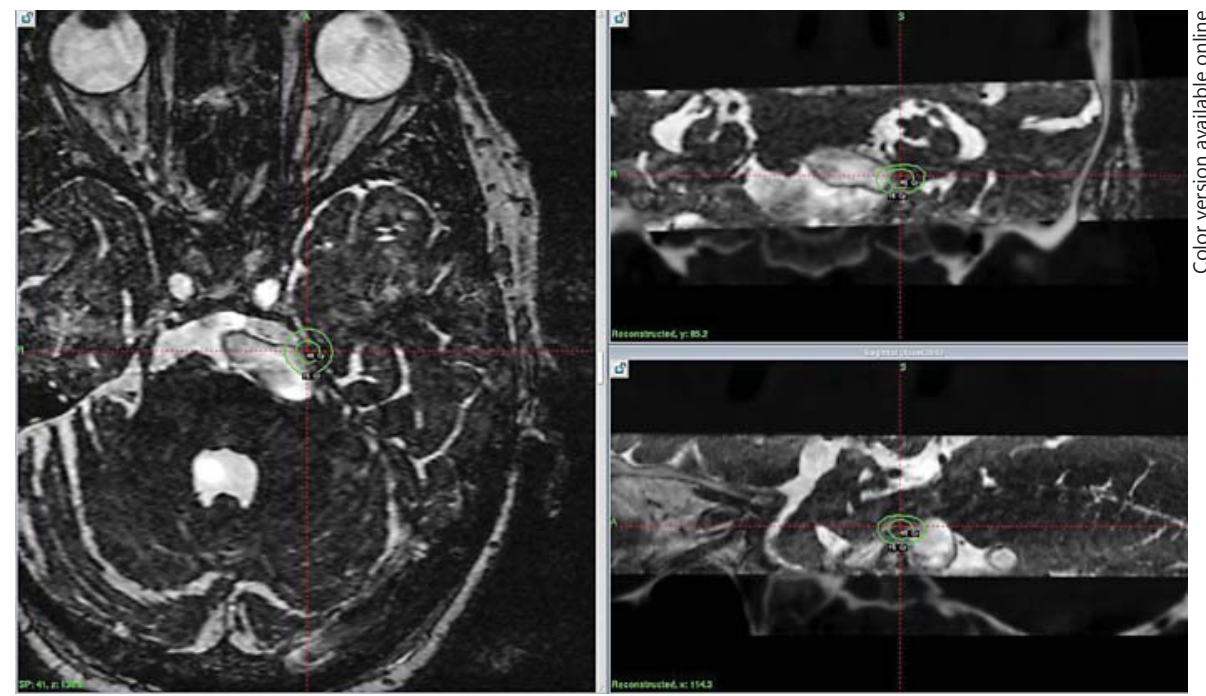

known as the Marseille target [41], adapted to this special anatomical condition.

Plugging was used in 8 patients $(27.6 \%)$. The doses were relatively high, with a median maximum dose of 90 Gy (range: 80-90 Gy). No patient received $<80 \mathrm{~Gy}$ at the $100 \%$ isodose point.

\section{Follow-Up and Assessment of Outcome}

The Marseille Mediterranean University as well as the Direction and Ethics Committee of Timone University Hospital (CPPRB1) approved our study. Follow-up information was obtained in two ways: direct clinical evaluation or telephone interview by the first author (C.T.), who was not involved in the selection of cases for treatment.

We evaluated the probability of initial pain cessation, the onset of sensory disturbance and the rate of recurrence. We analyzed data regarding latency periods until becoming pain free, having a recurrence or developing a sensory disturbance, paying attention to date every event, the use of medication and the need for further surgical procedures so as to accurately assess all the available information.

Pain was scored using 3 different scales: the Barrow Neurological Institute (BNI) pain scale (class I: 'no trigeminal pain, no medication'; class II: 'occasional pain, not requiring medication'; class IIIa: 'no pain, continued medication'; class IIIb: 'controlled with medication'; class IV: 'some pain, not adequately controlled with medication'; class V: 'severe pain, no pain relief'), the Burchiel scale (class I: 'pain free, no medication'; class II: 'pain free, on medication'; class IIIa: 'pain improved, no medication'; class IIIb: 'pain improved, on medication'; class IV: 'pain not improved') and the Regis scale (class I: 'no trigeminal pain, no medication'; class II: 'no pain, with medication'; class III: 'pain frequency reduction $>90 \%$ '; class IV: 'pain frequency reduction 50-90\%'; class V: 'no pain reduction'; class VI: 'pain worsening') [45-47]. For hypoesthesia we used the BNI facial hypoesthesia scale (class I: 'no facial numbness'; class II: 'mild facial numbness, not bothersome'; class III: 'facial numbness, somewhat bothersome'; class IV: 'facial numbness, very bothersome') [47]. For patients presenting facial sensory dysfunction, we also inquired about their quality of life re- lated to TN and whether this sensory problem was bothering them or not. We asked whether or not they had difficulties in mastication.

The patients and referring doctor were instructed to continue and not change the medication for at least 1 month and then were asked to diminish the drug doses progressively if the patients were pain free. A case report form was created and filled out prospectively since the first patient. The initial follow-up was based on a clinical evaluation - all patients being seen in person - for a proper evaluation of the safety and efficacy of GKS, followed by a neurological examination including facial sensibility and motility and corneal reflex at 3 months, 6 months and 1 year after the treatment, and then regularly once a year. Every clinical evaluation made by our medical team during follow-up was prospectively noted in the database so as to have continuous up-to-date information.

\section{Statistical Analysis}

Data were recorded using Microsoft Excel 2000. All statistical analyses were performed using R version 2.12.0 (R Foundation for Statistical Computing, Vienna, Austria). The R survival package was used for survival analysis.

First, a descriptive analysis of the recorded data was carried out among the MBA population. For the evaluation of outcomes such as initial pain cessation, hypoesthesia and recurrence, the time to the event was estimated by using the Kaplan-Meier method. A bivariate analysis was then performed to identify predictive factors among the collected variables. For qualitative variables, KaplanMeier curves were used to graphically represent survival among the different groups, and they were compared using the univariate $\log$ rank test. For all variables, the effects were estimated and tested by fitting univariate Cox proportional hazards regression models. Proportionality of hazards was assessed graphically by $\log \mathrm{cu}-$ mulative hazard plots.

For qualitative variables, the $\chi^{2}$ test was performed if valid, otherwise Fisher's exact test was used. For quantitative variables, the Mann-Whitney test was performed given the number of patients. All tests were two-sided, and $\mathrm{p}<0.05$ was judged to be significant. 
Table 1. Preoperative clinical demographic data

\begin{tabular}{lc}
\hline Patients with MBA-related TN & 29 \\
Gender & \\
Male & $13(44.8)$ \\
Female & $74.9(55.2)$ \\
Median age, years & $46.1(12.9-157)$ \\
Median duration of follow-up, months & \\
Side of pain & $10(34.5)$ \\
Right & $19(65.5)$ \\
Left & $1(3.4)$ \\
Bilateral & $12(41.4)$ \\
Pain distribution & $6(20.7)$ \\
V2 and V3 & $5(17.2)$ \\
V2 & $4(13.8)$ \\
V3 & $1(3.4)$ \\
V1 and V2 & $1(3.4)$ \\
V1-V3 & 0 \\
V1 & \\
V1 and V3 & \\
\hline
\end{tabular}

Figures in parentheses are percentages or ranges.

Table 2. General overview of previous surgeries and side effects related to other interventions

\begin{tabular}{ll}
\hline Patients with MBA-related TN & 29 \\
No prior surgery & $23(79.3)$ \\
Prior surgery & $6(20.7)$ \\
$\quad 1$ surgery & $2(6.9)$ \\
2 surgeries & $2(6.9)$ \\
$\geq 3$ surgeries & $2(6.9)$ \\
Type of prior surgery & $6(20.7)$ \\
Radiofrequency lesion & $5(17.2)$ \\
Balloon microcompression & $3(10.3)$ \\
MVD & $1(3.4)$ \\
Glycerol rhizotomy & 0 \\
Side effects from prior surgery & $6(20.7)$ \\
Facial sensibility before GKS & \\
Normal & $23(79.3)$ \\
Slight hypoesthesia & $6(20.7)$ \\
Severe hypoesthesia & 0 \\
Anesthesia & 0 \\
\hline
\end{tabular}

Figures in parentheses are percentages.

\section{Results}

The preoperative clinical demographic data are shown in table 1. In this series, 13 patients (44.8\%) were men and $16(55.2 \%)$ were women. The median age was 74.9 years (range: 51-90 years). The median follow-up period was 46.1 months (range: $12-157$ months). Trigeminal pain
Table 3. Postoperative clinical GKS-related characteristics

\begin{tabular}{ll}
\hline Patients with MBA-related TN & 29 \\
Post-GKS sensory dysfunction & $3(13.04)$ \\
Mild & $3(100)$ \\
Severe & 0 \\
BNI facial hypoesthesia scale (related to GKS treatment) \\
No facial numbness & $26(89.7)$ \\
Mild facial numbness & $3(10.3)$ \\
Facial numbness, somewhat bothersome & 0 \\
Facial numbness, very bothersome & 0 \\
Additional treatment(s) after GKS & $3(10.3)$ \\
1 treatment & $3(10.3)$ \\
2 treatments & 0 \\
$\geq 3$ treatments & 0 \\
Balloon microcompression & $2(6.9)$ \\
Radiofrequency lesion & $1(3.4)$ \\
MVD & 0 \\
Cortical stimulation & 0 \\
Glycerol rhizotomy & 0 \\
\hline
\end{tabular}

Figures in parentheses are percentages.

was more frequently encountered on the left side in 19 patients $(65.5 \%)$ compared with the right side in 10 patients (34.5\%). Only 1 patient (3.4\%) had bilateral pain. Pain was predominantly distributed in the V2 and V3 dermatomes of the trigeminal nerve (41.4\%), followed by only V2 (20.7\%), only V3 (17.2\%), V1 and V2 (13.8\%), V1-V3 (3.4\%), only V1 (3.4\%), and V1 and V3 (0\%).

Two patients (6.9\%) died from an unrelated cause but were not excluded from the study as they had had at least 1 year of follow-up. Twelve patients (41.4\%) were treated between July 1992 and December 2000 and 17 patients (58.6\%) between January 2001 and March 2010. Six patients $(20.7 \%)$ had undergone a prior surgical procedure, of which $2(6.9 \%)$ had only had 1 previous intervention, 2 (6.9\%) had undergone 2 previous surgeries, and 2 patients $(6.9 \%) \geq 3$ previous surgeries. The previous surgical modality used was radiofrequency lesioning in 5 patients (17.2\%), balloon microcompression in 3 patients $(10.3 \%)$ and MVD in 1 patient (3.4\%). Six patients (20.7\%) had sensory disturbance preoperatively, which in all cases was a slight hypoesthesia with no severe hypoesthesia or anesthesia caused by earlier (nerve ablation) procedure(s) (for a general overview of the previous surgeries and previous side effects related to other interventions, see table 2). GKS was the first surgical procedure in 23 patients (79.31\%).

The general postoperative outcome is shown in table 3. Table 4 shows the safety and efficacy of GKS over time, using the following parameters: initial pain cessation, hypoesthesia and the probability of recurrence. 
Table 4. Main parameters evaluating outcome characteristics after GKS

\begin{tabular}{lcc}
\hline & Patients, $\mathrm{n}(\%)$ & Median period (range) \\
\hline Pain free & $29(100)$ & $13.5(0-240)$ days \\
Hypoesthesia & $3(13.04)$ & $7(5-12)$ months \\
Recurrence & $7(24.1)$ & $10.75(3.8-12.6)$ months \\
\hline
\end{tabular}

\section{Initial Pain Cessation}

All 29 patients (100\%) were initially pain free; the average time to complete pain relief was 13.5 days (range: $0-240$ days). The actuarial rate of initial pain cessation at $0.5,1,2,3,4,5$ and 6 months was $62.1,79.3,93.1,93.1$, 93.1, 96.5 and $96.5 \%$, respectively. The pain distribution (in single vs. multiple territories) prior to GKS treatment was statistically significant for becoming pain free with $\mathrm{p}=0.01$ (hazard ratio, $\mathrm{HR}=0.37$; confidence interval, $\mathrm{CI}$, ranged between 0.17 and 0.8 ): 12 patients presented with trigeminal pain in 1 dermatome $(\log$ rank $p=0.03), 16$ patients in 2 dermatomes with a lower probability of being pain free $(\mathrm{p}=0.02 ; \mathrm{HR}=0.37$; CI ranged between 0.15 and 0.89$)$ and 1 patient in 3 dermatomes $(\mathrm{p}=0.06 ; \mathrm{HR}=$ 0.12 ; CI ranged between 0.01 and 1.10). Neither age ( $\mathrm{p}=$ $0.15)$ nor the duration of symptoms prior to treatment $(\mathrm{p}=0.90)$ nor the presence of atypical pain $(\mathrm{p}=0.94)$ nor previous surgeries $(p=0.73)$ nor $\operatorname{sex}(p=0.16)$ showed any statistically significant correlation. Figure 2 shows the actuarial probability of being initially pain free for the MBA population.

\section{Sensory Dysfunction after GKS}

No patient had any early postoperative complications after GKS. Of the 23 patients with no preoperative hypoesthesia, 3 (13\%) developed objective facial sensory loss, which occurred especially during the first 12 months after radiosurgery. Hypoesthesia onset was at a median of 7 months (range: 5-12 months). The patients reported mild, not bothersome hypoesthesia in all 3 cases. The actuarial probability of hypoesthesia onset at 6 months was $4.3 \%$, and at 1 year $13 \%$, remaining stable until 13 years.

We assessed hypoesthesia according to BNI facial hypoesthesia classes [44] (see table 3): class I in 20 patients (86.9\%), class II in 3 patients (13.1\%), class III in 0 patients and class IV in 0 patients. The 3 patients felt that their quality of life had improved after GKS and that the sensory dysfunction was a good trade-off for pain relief. Female patients statistically had a much lower probability of developing facial numbness, with a p value of 0.03 (in

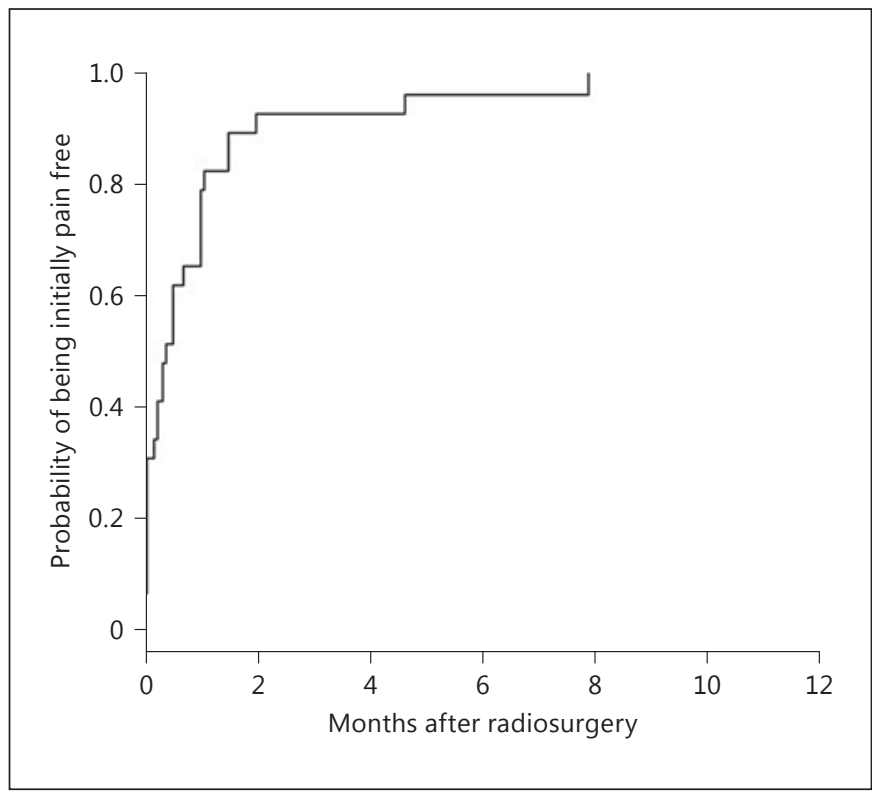

Fig. 2. Actuarial probability of initial pain cessation free in the population with MBA-related TN.

our series, no female patient with MBA-related TN had hypoesthesia after GKS). Hypoesthesia was predominant on the left side $(66.7 \% ; \mathrm{p}=0.912)$ and in the V2 dermatome $(\mathrm{p}=0.288)$. No patient developed a trigeminal motor deficit, or any other cranial nerve deficits, after GKS. No patient developed corneal sensory loss. Figure 3 shows the actuarial probability of hypoesthesia onset in the population with MBA-related TN.

\section{Maintaining Pain Relief after GKS and Management of Recurrence}

Seven $(24.13 \%)$ of the initially pain-free patients $(\mathrm{n}=$ 29) experienced at least 1 recurrence after GKS. The median time to pain recurrence was 10.75 months (range: 3.8-12.6 months). Figure 4 shows the actuarial probability of maintaining pain relief without medication for the 29 patients with MBA-related TN. This probability at 0.5 , 1 and 2 years was $93.1,79.3$ and $75.7 \%$, respectively, and remained stable until 12 years. Recurrence was especially related to preoperative pain within the $\mathrm{V} 3$ territory $(\mathrm{p}=$ 0.023 ), atypical pain ( $\mathrm{p}=0.011 ; \mathrm{HR}=6.92$; $\mathrm{CI}$ ranged between 1.54 and 31.12$)$ and age $(\mathrm{p}=0.005 ; \mathrm{HR}=0.89$; CI ranged between 0.83 and 0.97 ). The following parameters were not statistically significant: postoperative hypoesthesia $(\mathrm{p}=0.356 ; \mathrm{HR}=1)$, side of pain $(\mathrm{p}=0.561)$, previous surgical treatments $(\mathrm{p}=0.54)$, $\operatorname{sex}(\mathrm{p}=0.15)$ and durability of the symptoms before GKS $(\mathrm{p}=0.43)$. 


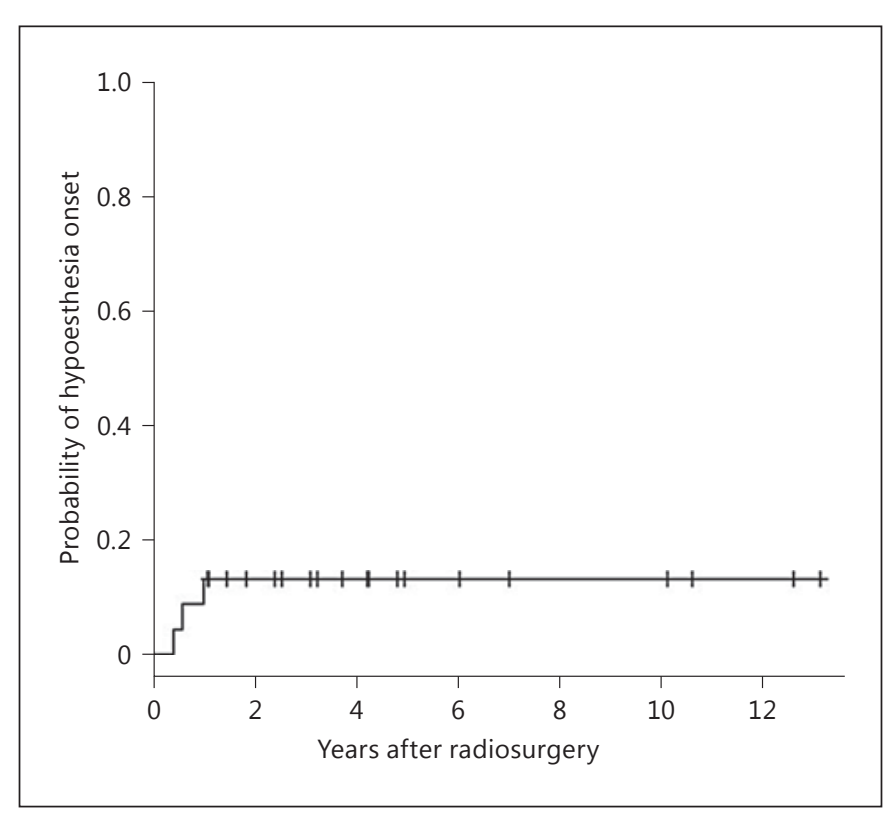

Fig. 3. Actuarial probability of hypoesthesia onset in the population with MBA-related TN.

Because of recurrent medically refractory pain, 3 patients $(10.34 \%)$ required further surgery (table 3 shows the postoperative characteristics). In our unit, the most frequent intervention after failed GKS was balloon microcompression, practiced in 2 patients (6.9\%), followed by thermocoagulation in 1 case $(3.4 \%)$.

\section{Evaluation of Outcome at the Last Follow-Up}

At the last follow-up, a good outcome was observed as follows: by the BNI scale in all 29 patients (100\%), by the Burchiel classification in 24 patients $(82.8 \%)$, and by the Regis classification in 28 patients ( $96.6 \%$; table 5$)$.

\section{Discussion}

The role of GKS in essential TN has evolved in the last 20 years, and this kind of surgery nowadays represents a less invasive technique $[48,49]$ for the treatment of intractable $\mathrm{TN}$, with results that vary from one study to another in terms of initial pain cessation as well as hypoesthesia and recurrence rates [37-39, 41, 42, 46, 50-55].

Regarding the etiology of TN, vascular compression is considered to be one of the major pathogenic factors [35]. Walter Dandy [56] was the first to note the association between TN and vascular compression as well as their causal relationship. Since his observation, approximately

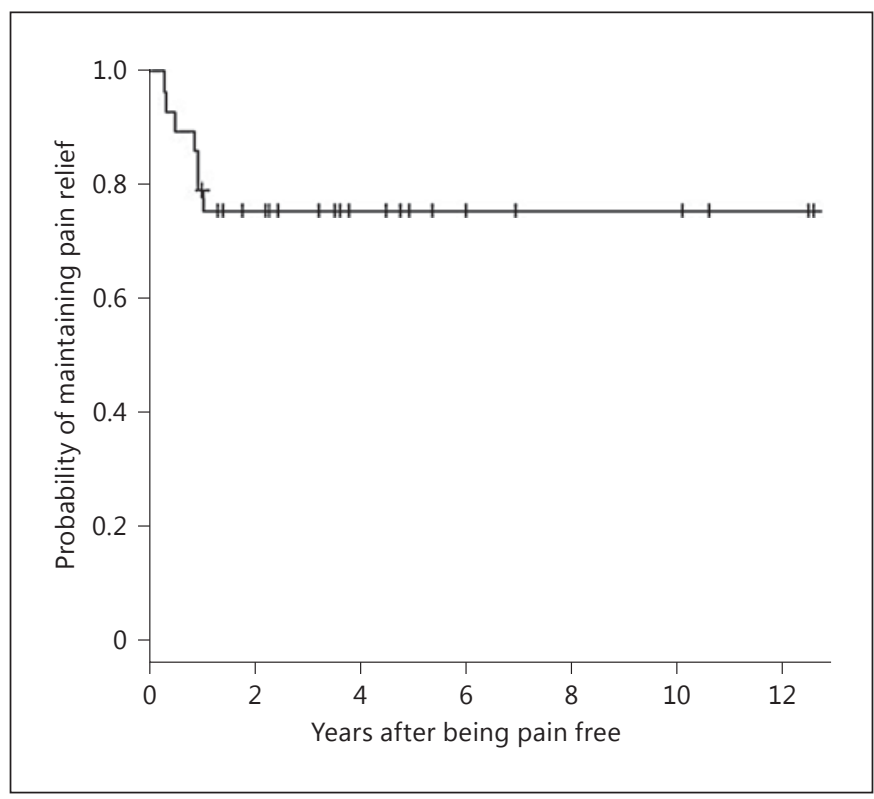

Fig. 4. Actuarial probability of maintaining pain relief in the population with MBA-related TN.

Table 5. Results at last follow-up by different evaluation scales

\begin{tabular}{lccc}
\hline & BNI & Burchiel & Regis \\
\hline Good result, n (\%) & $29(100)$ & $24(82.8)$ & $28(96.6)$ \\
Poor result, n (\%) & 0 & $5(17.2)$ & $1(3.4)$ \\
\hline
\end{tabular}

34 studies of TN caused by vertebral and/or basilar artery compression have been published, usually in the form of case reports $[12,16,18-23,25-29,31,57-59]$. In most of them, the incidence of this anatomical condition ranges from 0 to $2.8 \%$ [7, 13, 57, 60-62], with only 1 large series from Japan reporting a higher incidence (7.7\%) [31]. Park et al. [30] recently reported a percentage of $2 \%$ of the global population treated with GKS. In our study, the incidence was $4.47 \%$.

MVD has been the accepted modality of treatment for TN caused by neurovascular compression [63]. Thus, a few articles in the literature treated the subject of MVD in the case of MBA compression causing TN. Linskey et al. [12] described a series of 31 patients of whom all were pain free (off medication) immediately after surgery and $90 \%$ were pain free (off medication) at the time of the report; 3 patients in that series had had pain recurrence. The overall 1-, 3-and 10-year rates of patients being pain free 
(off medication) were 96, 92 and 86\%, respectively. In terms of toxicity, $51.6 \%$ of the patients had minor trigeminal hypoesthesia/hypoalgesia preoperatively, and $41.9 \%$ of the patients had newly or mildly worsened minor hypoesthesia/hypoalgesia postoperatively, with only 1 patient having masseter weakness and major hypoesthesia (a patient who underwent a complete nerve section). Other deficits were trochlear or abducens nerve palsy (22.6\%), hearing loss (12.9\%) and aseptic meningitis (29\%).

Ogawa et al. [58] reported the use of a synthetic vascular graft sutured to the clival dura to move the vessel away from the cranial nerves. Stone et al. [59] used a silicone sling sutured to the petrous dura to reposition the basilar artery away from the trigeminal nerve. Takamiya et al. [27] used a fenestrated clip and decompressed the nerves. Other authors, such as Goel and Shah [17], proposed foramen magnum decompression in a particular case of ectatic basilar artery and basilar invagination. There was immediate relief from the neuralgic pain and no recurrence observed at 18 months.

Park et al. [30] recently published the first series in the literature concerning MBA-related TN treated with GKS. In their population, $75 \%$ of the patients achieved initial pain relief that was adequate or better (BNI pain scale classes I-IIIb), with a probability of maintaining pain relief of 53,38 and $10 \%$ at 1,2 and 5 years, respectively. Some degree of facial sensory dysfunction occurred in $10 \%$ of the patients. Fourteen patients $(70 \%)$ underwent an additional surgical procedure.
In our series, all the 29 patients (100\%) had initial pain cessation without medication in a median time of 13.5 days (range: 0-240 days). The hypoesthesia rate was low, with hypoesthesia present in only 3 patients (13.04\%). Recurrent pain was observed in 7 patients $(24.1 \%)$, of whom $3(10.3 \%)$ needed further surgery.

\section{Conclusions}

GKS can be used as a first- and/or second-line treatment for TN caused by MBA compression. The rarity of complications even in the long run and the considerable probability of a long-lasting effect make GKS a pragmatic surgical first-intention treatment alternative for MBArelated $\mathrm{TN}$.

\section{Acknowledgments}

This study was funded by the Centre Hospitalier Universitaire La Timone Assistance Publique-Hôpitaux de Marseille, France.

\section{Disclosure Statement}

J.R. received congress organization sponsoring from Accuray, Brainlab, Elekta and Varian. The other authors report no conflict of interest.

\section{References}

1 André N: Observations pratiques sur les maladies de l'urethre: et sur plusieurs faits convulsifs, \& la guérison de plusieurs maladies chirurgicales, avec la décomposition d'un remède propre à réprimer la dissolution gangréneuse \& cancéreuse, \& à la réparer; avec des principes qui pourront servir à employer les différents caustiques. Paris, Delaguette, 1976 (1756).

2 Alexander E, Loeffler JS, Lunsford DL: Stereotactic Radiosurgery. New York, McGrawHill, 1993, vol 1, p 254.

3 Haines SJ, Jannetta PJ, Zorub DS: Microvascular relations of the trigeminal nerve: an anatomical study with clinical correlation. J Neurosurg 1980;52:381-386.

4 Hamlyn PJ, King TT: Neurovascular compression in trigeminal neuralgia: a clinical and anatomical study. J Neurosurg 1992;76:948954
5 Jannetta PJ: Arterial compression of the trigeminal nerve at the pons in patients with trigeminal neuralgia. J Neurosurg 1967;26 (suppl):159-162.

6 Lorenzoni JG, et al: Neurovascular compression anatomy and pain outcome in patients with classic trigeminal neuralgia treated by radiosurgery. Neurosurgery 2008;62:368375 , discussion $375-376$.

7 Bederson JB, Wilson CB: Evaluation of microvascular decompression and partial sensory rhizotomy in 252 cases of trigeminal neuralgia. J Neurosurg 1989;71:359-367.

8 Burchiel KJ, et al: Comparison of percutaneous radiofrequency gangliolysis and microvascular decompression for the surgical management of tic douloureux. Neurosurgery 1981;9:111-119.

9 Goya T, Wakisaka S, Kinoshita K: Microvascular decompression for trigeminal neuralgia with special reference to delayed recurrence. Neurol Med Chir (Tokyo) 1990;30:462-467.
10 Jannetta PJ: Microvascular decompression of the trigeminal root entry zone: theoretical considerations, operative anatomy, surgical technique, and results; in Rovit RL, Murali R, Janetta PJ (eds): Trigeminal Neuralgia. Baltimore, Williams \& Wilkins, 1990, pp 201-222.

11 Kolluri S, Heros RC: Microvascular decompression for trigeminal neuralgia: a five-year follow-up study. Surg Neurol 1984;22:235240.

12 Linskey ME, Jho HD, Jannetta PJ: Microvascular decompression for trigeminal neuralgia caused by vertebrobasilar compression. J Neurosurg 1994;81:1-9.

13 Sindou M, Amrani F, Mertens P: Décompression vasculaire microchirurgicale pour névralgie du trijumeau: comparaison de deux modalités techniques et déductions physiopathologiques. Etude sur 120 cas. Neurochirurgie 1990;36:16-25, discussion 25-26.

Tuleasca/Carron/Resseguier/Donnet/ Roussel/Gaudart/Levivier/Régis 
14 Sindou M: Microvascular decompression for trigeminal neuralgia; in Sindou M (ed): Practical Handbook of Neurosurgery. Vienna, Springer, 2009, pp 1448-1462.

15 Jannetta PJ: Observations on the etiology of trigeminal neuralgia, hemifacial spasm, acoustic nerve dysfunction and glossopharyngeal neuralgia: definitive microsurgical treatment and results in 117 patients. Neurochirurgia (Stuttg) 1977;20:145-154.

16 Corkill G, Sarwar M, Virapongse C: Evolution of dolichoectasia of the vertebrobasilar system as evidenced by serial computed tomography. Surg Neurol 1982;18:262-266.

17 Goel A, Shah A: Trigeminal neuralgia in the presence of ectatic basilar artery and basilar invagination: treatment by foramen magnum decompression. J Neurosurg 2009;111:12201222 .

18 Grigoryan YA, Dreval ON, Michailova SI: Painful tic convulsif caused by a contralateral vertebral artery. Surg Neurol 1991;35:471-474.

19 Harsh GR 4th, et al: Magnetic resonance imag ing of vertebrobasilar ectasia in tic convulsif: case report. J Neurosurg 1991;74:999-1003.

20 Hashimoto $\mathrm{K}$, et al: Trigeminal neuralgia caused by a dolichoectatic vertebrobasilar artery: a case report. Rinsho Hoshasen 1987;32 331-334.

21 Koyanagi S, et al: Bilateral fenestrations of the vertebrobasilar artery with trigeminal neuralgia: case report. Neurol Med Chir (Tokyo) 1991;31:995-998.

22 Lye RH: Basilar artery ectasia: an unusual cause of trigeminal neuralgia. J Neurol Neurosurg Psychiatry 1986;49:22-28.

23 Miner ME, et al: Trigeminal neuralgia due to dolichoectasia: angiographic and CT findings in a patient with the EEC syndrome. Neuroradiology 1980;20:163-166.

24 Niizuma H, Ikeda S, Ohyama H: Trigeminal neuralgia and hemifacial spasm caused by the compression of tortuous vertebro-basilar system: a case report (author's transl) (in Japanese). No Shinkei Geka 1981;9:1167-1170.

25 Petty PG, Southby R: Vascular compression of lower cranial nerves: observations using microsurgery, with particular reference to trigeminal neuralgia. Aust NZ J Surg 1977;47: 314-320.

26 Suzuki S, et al: New method of MVD using a vascular tape for neurovascular compression involving the vertebrobasilar artery: report of two cases. Neurol Med Chir (Tokyo) 1990;30: 1020-1023.

27 Takamiya Y, et al: Trigeminal neuralgia and hemifacial spasm caused by a tortuous vertebrobasilar system. Surg Neurol 1985;24:559-562.

28 Waga S, Morikawa A, Kojima T: Trigeminal neuralgia: compression of the trigeminal nerve by an elongated and dilated basilar artery. Surg Neurol 1979;11:13-16.

29 Yoshida M, Asano M: Direct compression by megadolichobasilar anomaly as a cause of trigeminal neuralgia: a case diagnosed by MRI Tohoku J Exp Med 1994;172:327-332.
30 Park KJ, et al: Outcomes of Gamma Knife surgery for trigeminal neuralgia secondary to vertebrobasilar ectasia. J Neurosurg 2012;116: 73-81.

31 Miyazaki S, et al: Trigeminal neuralgia due to compression of the trigeminal root by a basilar artery trunk: report of 45 cases. Neurol Med Chir (Tokyo) 1987;27:742-748.

32 Regis J, Tuleasca C: Fifteen years of Gamma Knife surgery for trigeminal neuralgia in the Journal of Neurosurgery: history of a revolution in functional neurosurgery. J Neurosurg 2011;115(suppl):2-7.

33 Tuleasca C, et al: Patterns of pain-free response in 497 cases of classic trigeminal neuralgia treated with Gamma Knife surgery and followed up for at least 1 year. J Neurosurg 2012;117(suppl):181-188.

34 Flickinger JC, et al: Does increased nerve length within the treatment volume improve trigeminal neuralgia radiosurgery? A prospective double-blind, randomized study. Int J Radiat Oncol Biol Phys 2001;51:449-454.

35 Foote KD, et al: Analysis of risk factors associated with radiosurgery for vestibular schwannoma. J Neurosurg 2001;95:440-449.

36 Frazier $\mathrm{CH}$ : Operation for the radical cure of trigeminal neuralgia: analysis of five hundred cases. Ann Surg 1928;88:534-547.

37 Brisman R, Mooij R: Gamma knife radiosurgery for trigeminal neuralgia: dose-volume histograms of the brainstem and trigeminal nerve. J Neurosurg 2000;93(suppl 3):155158.

38 Dhople AA, et al: Long-term outcomes of Gamma Knife radiosurgery for classic trigeminal neuralgia: implications of treatment and critical review of the literature. Clinical article. J Neurosurg 2009;111:351-358.

39 Massager N, et al: Gamma knife surgery for idiopathic trigeminal neuralgia performed using a far-anterior cisternal target and a high dose of radiation. J Neurosurg 2004;100:597605.

40 Pollock BE: Radiosurgery for trigeminal neuralgia: is sensory disturbance required for pain relief? J Neurosurg 2006;105(suppl): 103-106.

41 Regis J, et al: Prospective controlled trial of gamma knife surgery for essential trigeminal neuralgia. J Neurosurg 2006;104:913-924.

42 Verheul JB, et al: Gamma Knife surgery for trigeminal neuralgia: a review of 450 consecutive cases. J Neurosurg 2010;113(suppl): 160-167.

43 Headache Classification Subcommittee of the International Headache Society: The International Classification of Headache Disorders, ed 2. Cephalalgia 2004;24(suppl):9-160.

44 Eller JL, Raslan AM, Burchiel KJ: Trigeminal neuralgia: definition and classification. Neurosurg Focus 2005;18:E3.

45 Miller JP, et al: Predictors of long-term success after microvascular decompression for trigeminal neuralgia. J Neurosurg 2009;110: 620-626.
46 Regis J, et al: Radiosurgery in trigeminal neuralgia: long-term results and influence of operative nuances. Neurochirurgie 2009;55: 213-222.

47 Rogers CL, et al: Gamma knife radiosurgery for trigeminal neuralgia: the initial experience of the Barrow Neurological Institute. Int J Radiat Oncol Biol Phys 2000;47:1013-1019.

48 Cruccu G, et al: AAN-EFNS guidelines on trigeminal neuralgia management. Eur J Neurol 2008; 15:1013-1028.

49 Gronseth G, et al: Practice parameter: the diagnostic evaluation and treatment of trigeminal neuralgia (an evidence-based review): report of the Quality Standards Subcommittee of the American Academy of Neurology and the European Federation of Neurological Societies. Neurology 2008;71:1183-1190.

50 Kondziolka D, et al: Gamma Knife stereotactic radiosurgery for idiopathic trigeminal neuralgia. J Neurosurg 2010;112:758-765.

51 Maesawa S, et al: Clinical outcomes after stereotactic radiosurgery for idiopathic trigeminal neuralgia. J Neurosurg 2001;94:14-20.

52 Matsuda S, et al: Gamma knife radiosurgery for trigeminal neuralgia: the dry-eye complication. J Neurosurg 2002;97(suppl):525-528.

53 Nicol B, et al: Gamma knife radiosurgery using $90 \mathrm{~Gy}$ for trigeminal neuralgia. J Neurosurg 2000;93(suppl 3):152-154.

54 Pollock BE, et al: Results of repeated gamma knife radiosurgery for medically unresponsive trigeminal neuralgia. J Neurosurg 2000; 93(suppl 3):162-164.

55 Pollock BE, et al: Stereotactic radiosurgery for idiopathic trigeminal neuralgia. J Neurosurg 2002;97:347-353.

56 Dandy W: Concerning the cause of trigeminal neuralgia. Am J Surg 1934;24:447-455.

57 Dandy W: Intracranial Arterial Aneurysms. Ithaca, Comstock, 1944

58 Ogawa A, et al: Repositioning of the tortuous vertebrobasilar artery for trigeminal neuralgia: a technical note. Surg Neurol 1992;38: 232-235.

59 Stone JL, Lichtor T, Crowell RM: Microvascular sling decompression for trigeminal neuralgia secondary to ectatic vertebrobasilar compression: case report. J Neurosurg 1993 79:943-945.

60 Apfelbaum RI: Surgery for tic douloureux. Clin Neurosurg 1983;31:351-368.

61 Klun B: Microvascular decompression and partial sensory rhizotomy in the treatment of trigeminal neuralgia: personal experience with 220 patients. Neurosurgery 1992;30:4952.

62 Piatt JH Jr, Wilkins RH: Treatment of tic douloureux and hemifacial spasm by posterior fossa exploration: therapeutic implications of various neurovascular relationships. Neurosurgery 1984;14:462-471.

63 Jannetta PJ: Microsurgical management of trigeminal neuralgia. Arch Neurol 1985;42: 800 . 